Cite this: Phys. Chem. Chem. Phys., 2013, 15, 824

Received 19th July 2012, Accepted 13th November 2012 DOI: $10.1039 /$ c2cp43576d

www.rsc.org/pccp

\section{Characterization of the $\mathrm{MgO}^{2+}$ dication in the gas phase: electronic states, spectroscopy and atmospheric implications $\dagger$}

\author{
R. Linguerri, ${ }^{a}$ M. Hochlaf, ${ }^{\star a}$ M.-C. Bacchus-Montabonel ${ }^{b}$ and M. Desouter-Lecomte ${ }^{c}$
}

Franzreb and Williams at Arizona State University detected recently the $\mathrm{MgO}^{2+}$ molecular species in the gas phase. Here we report a very detailed theoretical investigation of the low-lying electronic states of this dication including their potentials, spin-orbit, rotational and radial couplings. Our results show that the potential energy curves of the dicationic electronic states have deep potential wells. This confirms that this dication does exist in the gas phase; it is a thermodynamically stable molecule in its ground state, and it has several excited long-lived metastable states. The potential energy curves are used then to predict a set of spectroscopic parameters for the bound states of $\mathrm{MgO}^{2+}$. We have also incorporated these potentials, rotational and radial couplings in dynamical calculations to derive the cross sections for the charge transfer $\mathrm{Mg}^{2+}+\mathrm{O} \rightarrow \mathrm{Mg}^{+}+\mathrm{O}^{+}$reaction in the $1-10^{3} \mathrm{eV}$ collision energy domain via formation-decomposition of the $\mathrm{MgO}^{2+}$ dication. Our work shows the role of $\mathrm{MgO}^{2+}$ in the Earth ionosphere and more generally in atmospheric processes in solar planets, where this reaction efficiently participates in the predominance of $\mathrm{Mg}^{+}$cations in these media compared to $\mathrm{Mg}$ and $\mathrm{Mg}^{2+}$.

\section{Introduction}

Magnesium and magnesium oxide (neutral and ionic) are of great importance for combustion ${ }^{1}$ and atmospheric and planetary chemistry, ${ }^{2,3}$ where they are involved in a multitude of ionmolecule reactions. Indeed, $\mathrm{Mg}$ is among the most abundant cosmic metals and it is a major constituent of chondritic meteorites. ${ }^{4,5}$ In Earth's atmosphere, the $\mathrm{Mg}^{+}$cation is 4 to 12 times more abundant than neutral Mg. ${ }^{6,7}$ Magnesium in the upper portions of Earth's atmosphere is provided by meteoritic ablation, where it is present as atomic and ionized $\mathrm{Mg}^{2+}$, especially in the ionosphere. $\mathrm{Mg}^{2+}$ travelling through the lower atmosphere layers should react, at least with $\mathrm{O}$, and contribute to the increase in the $\mathrm{Mg}^{+} / \mathrm{Mg}$ ratio. Several scenarios were proposed to explain the unusual $\mathrm{Mg}^{+} / \mathrm{Mg}$ ratio based on ion-molecule charge transfer

\footnotetext{
${ }^{a}$ Université Paris-Est, Laboratoire Modélisation et Simulation Multi Echelle, MSME UMR 8208 CNRS, 5 bd Descartes, 77454 Marne-la-Vallée, France. E-mail: hochlaf@univ-mlv.fr; Fax: +33 1609573 20; Tel: +33 160957319

${ }^{b}$ Université de Lyon (Lyon I), Laboratoire de Spectrométrie Ionique et Moléculaire, CNRS UMR 5579, 43. Bd. du 11 Novembre 1918, 69622 Villeurbanne cedex, France

${ }^{c}$ Laboratoire de Chimie Physique, Bât 349, Univ-Paris Sud et CNRS-UMR 8000, F-91405 Orsay Cedex, France

† Electronic supplementary information (ESI) available. See DOI: 10.1039/ c2cp43576d
}

reactions. ${ }^{8}$ As explained in ref. $9-11, \mathrm{Mg}^{2+}$ ions are unstable in the presence of $\mathrm{O}_{2}$ since they are immediately converted into $\mathrm{Mg}^{+}$ ions through the $\mathrm{Mg}^{2+}+\mathrm{O}_{2} \rightarrow \mathrm{Mg}^{+}+\mathrm{O}_{2}^{+}$reaction. For the conversion of $\mathrm{Mg}$ into $\mathrm{Mg}^{+}$, the implication of $\mathrm{O}, \mathrm{O}_{2}, \mathrm{O}_{3}$ and their ionized species are invoked. For instance, we can cite the following reactions:

$$
\begin{aligned}
\mathrm{Mg}+\mathrm{O}_{2}^{+} & \rightarrow \mathrm{MgO}^{+}+\mathrm{O} \\
\mathrm{MgO}^{+}+\mathrm{O} & \rightarrow \mathrm{Mg}^{+}+\mathrm{O}_{2} \\
\mathrm{Mg}+\mathrm{O}_{2}^{+} & \rightarrow \mathrm{Mg}^{+}+\mathrm{O}_{2} \\
\mathrm{Mg}^{+}+\mathrm{O}_{3} & \rightarrow \mathrm{MgO}^{+}+\mathrm{O}_{2} \\
\mathrm{Mg}+\mathrm{O}^{+} & \rightarrow \mathrm{Mg}^{+}+\mathrm{O}
\end{aligned}
$$

The most commonly accepted reaction for $\mathrm{Mg}-\mathrm{Mg}^{+}$conversion is reaction (3). ${ }^{12}$ At $T=300 \mathrm{~K}$, Ferguson ${ }^{13}$ measured a rate constant of $1.2 \times 10^{-9} \mathrm{~cm}^{3} \mathrm{~s}^{-1}$. In 2008 , Yazidi et al. ${ }^{14}$ investigated the corresponding reaction pathways. For reaction (2), Rowe et al..$^{9}$ evaluated the rate constant to be $1 \times 10^{-10} \mathrm{~cm}^{3} \mathrm{~s}^{-1}$ at $T=300 \mathrm{~K}$. Very recently, Ben Houria et al. ${ }^{15}$ showed that ionmolecule reactions between $\mathrm{Mg}$ and $\mathrm{O}_{3}{ }^{+}$may lead also to the formation of $\mathrm{Mg}^{+}$but in less extent because of the lower abundance of ozone in the atmosphere compared to $\mathrm{O}_{2}$ and $\mathrm{O}$. For reaction (4), the measured rate constant is $2.3 \times$ $10^{-10} \mathrm{~cm}^{3} \mathrm{~s}^{-1}$ (at $\left.T=300 \mathrm{~K}\right) .{ }^{16}$ Finally, a very small rate constant 


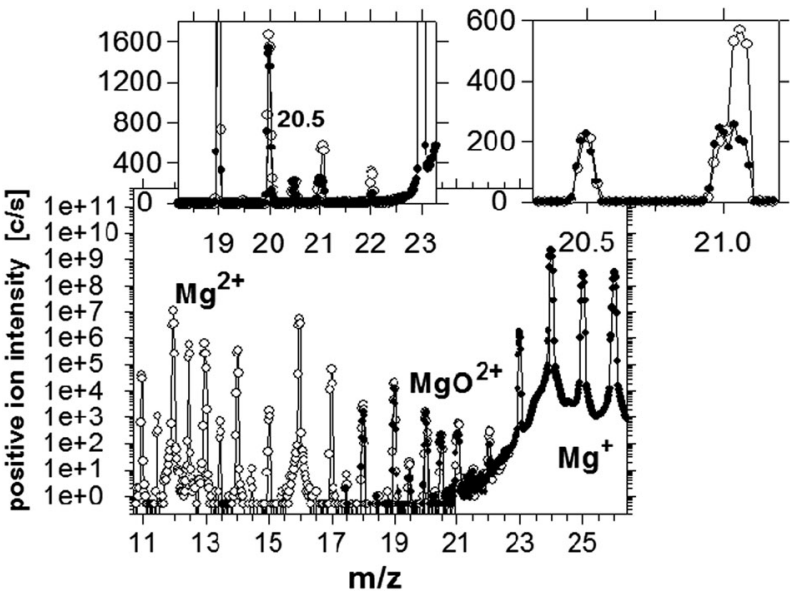

Fig. 1 Two positive ion mass spectra acquired for prolonged $0.43 \mu \mathrm{A}, 17 \mathrm{keV}{ }^{16} \mathrm{O}^{-}$ ion surface bombardment of a piece of magnesium metal (sample potential $4500 \mathrm{~V}$, count time $2 \mathrm{~s}$ per data point, Cameca IMS $3 \mathrm{f}$ mass spectrometer). The data shown are provided from courtesy of Klaus Franzreb and Peter Williams (Arizona State University, 2007, unpublished). ${ }^{25} \mathrm{Mg}^{16} \mathrm{O}^{2+}$ is observed at half-integer $\mathrm{m} / \mathrm{z} 20.5$ (shown in the two insets on a linear intensity scale). The ion signal at $m / z 20$ is dominated by ${ }^{24} \mathrm{Mg}^{16} \mathrm{O}^{2+}$. The assignments to $\mathrm{MgO}^{2+}$ are supported by the isotopic abundance of magnesium. See the text for further details.

is estimated by Ferguson ${ }^{13}$ for the charge transfer reaction $\mathrm{Mg}+\mathrm{O}^{+} \rightarrow \mathrm{Mg}^{+}+\mathrm{O}$ (reaction (5)), so that it can be ruled out for the explanation of the large abundance of $\mathrm{Mg}^{+}$in the atmosphere. Nevertheless, nothing is found in the literature relative to the $\mathrm{Mg}^{2+}+\mathrm{O} \rightarrow \mathrm{Mg}^{+}+\mathrm{O}^{+}$reaction that may contribute to the increase in the $\mathrm{Mg}^{+} / \mathrm{Mg}$ ratio. More specifically, the existence of $\mathrm{MgO}^{2+}$ is not definitely established either experimentally or theoretically despite both neutral $\mathrm{MgO}$ and $\mathrm{MgO}^{+}$ions being widely studied (see ref. 17 and 18 for more details).

The present theoretical treatment focuses on the diatomic dication $\mathrm{MgO}^{2+}$ and the $\mathrm{Mg}^{2+}+\mathrm{O} \rightarrow \mathrm{Mg}^{+}+\mathrm{O}^{+}$thermodynamically favorable reaction. In 2007, this exotic diatomic dication was produced in the gas phase in a sputtering experiment by Franzreb and Williams, where it was detected using a magnetic-sector mass spectrometer. ${ }^{19}$ We thank the authors for allowing us to show their mass spectra as Fig. 1.

More recently $\mathrm{MgO}^{2+}$ might have also been observed by Vella et al. using atom probe time-of-flight mass spectrometry. ${ }^{21}$ It should be noted that the low-intensity ion peak at mass $(\mathrm{m} / \mathrm{z}) 20$ in Fig. 4a therein was not assigned by the authors, since the broad background (tail) was too high to detect the other less-abundant expected isotopologues of $\mathrm{MgO}^{2+}$ at masses 20.5 and $21 .^{22}$

Fig. 1 displays the mass spectra measured by Franzreb and Williams for $17 \mathrm{keV}^{16} \mathrm{O}^{-}$sputtering of a piece of magnesium metal. The Mg surface had been sputter-cleaned and dynamically oxidized by prolonged oxygen ion bombardment. The data shown as open symbols were taken after several minutes of pre-bombardment and sputter cleaning, whereas the second (repeat) measurement shown as full symbols was done after (much) more extensive sputter cleaning of the oxidized Mg surface. The two mass spectra are shown both in semi-logarithmic and in linear presentation (insets). The ion signals are displayed as absolute intensities in units of single ion counts per second (c/s); the count time was $2 \mathrm{~s}$ per data point. The ion signal at half-integer $\mathrm{m} / \mathrm{z} 20.5$ is attributed to ${ }^{25} \mathrm{Mg}^{16} \mathrm{O}^{2+}$. A different assignment of the ion signal at $\mathrm{m} / \mathrm{z} 20.5$ to either ${ }^{41} \mathrm{~K}^{2+}$ or ${ }^{24} \mathrm{Mg}^{16} \mathrm{O}^{1} \mathrm{H}^{2+}$ (ref. 23) has been ruled out because of the low ion signal or background at $\mathrm{m} / z 19.5$ and 21.5 , respectively. The ion signal at $\mathrm{m} / \mathrm{z} 20$ is dominated by ${ }^{24} \mathrm{Mg}^{16} \mathrm{O}^{2+}$. The ion signals at $\mathrm{m} / \mathrm{z} 21$ are a broad, unresolved (open symbols) or a barely/poorly resolved (full symbols) 'double peak' (with the shoulder or the peak of ${ }^{26} \mathrm{Mg}^{16} \mathrm{O}^{2+}$ on the left side with roughly $250 \mathrm{c} / \mathrm{s}$ at $\mathrm{m} / \mathrm{z} 21.0$ (see full symbols in the right-side inset)). These three assignments to $\mathrm{MgO}^{2+}$ are supported by the natural isotopic abundance of magnesium (of about $79 \%$ vs. $10 \%$ vs. $11 \%$ for ${ }^{24} \mathrm{Mg} v$ s. ${ }^{25} \mathrm{Mg} v$ vs. ${ }^{26} \mathrm{Mg}$ ). The diatomic trication $\mathrm{MgO}^{3+}$ could not be detected at $\mathrm{m} / \mathrm{z} 13.3$ (or 13.7). Several atomic dications from contaminants (note again that the full data points were taken in a repeat measurement for improved sputter-cleaning of the $\mathrm{Mg}$ surface) were also observed at half-integer $m / z$ values, including $\mathrm{Na}^{2+}$ (at $m / z$ 11.5), $\mathrm{Al}^{2+}$ (at $m / z 13.5$ ), $\mathrm{Si}^{2+}$ (at $m / z 14.5$ ), $\mathrm{Cl}^{2+}$ (at $m / z 17.5,18.5$ ) and $\mathrm{K}^{2+}$ (at $m / z$ 19.5). Note that the interfering superimposed signal of ${ }^{41} \mathrm{~K}^{2+}$ at $\mathrm{m} / \mathrm{z} 20.5$ is negligibly small as compared to that of ${ }^{25} \mathrm{Mg}^{16} \mathrm{O}^{2+}$.

Theoretically, the $\mathrm{MgO}^{2+}$ dication had been investigated previously by Kolbuszewski and Wright ${ }^{24}$ at the multireference single- and double-excitation (MRD-CI) level of theory, as part of a systematic study of the thermodynamic stability of the ground states of $\mathrm{MgX}^{2+}(\mathrm{X}=\mathrm{N}, \mathrm{O}$ and $\mathrm{F})$ dications. These authors found that the $\mathrm{MgO}^{2+}$ dication has the largest kinetic stability, with an effective dissociation barrier of $1.33 \mathrm{eV}$. They deduced an equilibrium distance of 4.126 bohr and an harmonic frequency of $358 \mathrm{~cm}^{-1}$.

In the present work we have calculated the potential energy curves corresponding to the lowest electronic states of $\mathrm{MgO}^{2+}$ at the MRCI/aug-cc-pV5Z level of theory. Using these highly correlated wavefunctions, we deduced the radial and the rotational couplings between these electronic states. For bound states, sets of spectroscopic constants were then obtained. The potentials and the couplings were incorporated later into dynamical calculations using both semi-classical and quantum methods to evaluate the cross sections followed by an average over a Maxwellian velocity distribution to estimate the rate constant for the $\mathrm{Mg}^{2+}+\mathrm{O} \rightarrow \mathrm{Mg}^{+}+\mathrm{O}^{+}$charge transfer reaction. Finally, the implication of our findings for the atmospheric chemistry is discussed.

\section{Computational details}

\section{Electronic structure calculations}

Our theoretical study of the $\mathrm{MgO}^{2+}$ dication consists of ab initio calculations of the adiabatic potential energy curves (PECs) of the electronic states correlating to the four lowest dissociation limits i.e. the charge separation limit $\mathrm{O}^{+}\left({ }^{4} \mathrm{~S}_{\mathrm{u}}\right)+\mathrm{Mg}^{+}\left({ }^{2} \mathrm{~S}_{\mathrm{g}}\right)$, the charge retaining channels $\mathrm{O}\left({ }^{3} \mathrm{P}_{\mathrm{g}}\right)+\mathrm{Mg}^{2+}\left({ }^{1} \mathrm{~S}_{\mathrm{g}}\right)$ and $\mathrm{O}\left({ }^{1} \mathrm{D}_{\mathrm{g}}\right)+$ $\mathrm{Mg}^{2+}\left({ }^{1} \mathrm{~S}_{\mathrm{g}}\right)$ and the excited charge separation dissociation $\mathrm{O}^{+}\left({ }^{2} \mathrm{D}_{\mathrm{u}}\right)+\mathrm{Mg}^{+}\left({ }^{2} \mathrm{~S}_{\mathrm{g}}\right)$. For the electronic calculations, we described the magnesium and the oxygen atoms with the aug-cc-pV5Z basis set. $^{25-28}$ This results in 258 contracted Gaussian 
functions. These calculations were performed using the complete active space self-consistent field (CASSCF) approach, ${ }^{29,30}$ followed by the internally contracted multi-reference configuration interaction (MRCI) ${ }^{31,32}$ technique, as implemented in the MOLPRO code. ${ }^{33}$ In the CASSCF calculations, all electronic states were averaged together with equal weights. The CASSCF active space was constructed after excitation of all valence electrons into all valence molecular orbitals, hence it consists of six electrons in eight active orbitals. All molecular orbitals were optimized. At the MRCI level, all configuration state functions (CSFs) from the CASSCF vector were taken as a reference, resulting, for instance, in more than $8.7 \times 10^{6}$ uncontracted CSFs per $C_{2 \mathrm{v}}$ symmetry when computing the triplet states of $\mathrm{MgO}^{2+}$. In total, we computed two $\Sigma^{+}$, one $\Pi$, and one $\Delta$ singlet states; two $\Sigma^{-}$, two $\Pi$, and one $\Delta$ triplets; and one ${ }^{5} \Sigma^{-}$ state. Finally, the radial and rotational couplings between the lowest electronic states were evaluated at the MRCI level. The spin-orbit coupling matrix elements in Cartesian coordinates were computed, where the MRCI wavefunctions were used as the multi-electron basis for the two-step spin-orbit coupling calculation $^{34,35}$ at the level of Breit-Pauli Hamiltonian. ${ }^{36}$

For the bound electronic states, the rovibrational energies were obtained using either the force field and second order perturbation theory or a variational treatment to solve the onedimensional Schrödinger equation for the nuclear motion problem. ${ }^{37,38}$ We deduced a set of spectroscopic constants for the bound states of $\mathrm{MgO}^{2+}$.

\section{Dynamical calculations}

The collision dynamics were performed using semi-classical and quantum methods in diabatic representation. Both of them were widely described elsewhere (see for instance ref. 39 for more details). For numerical semi-classical treatments, we used the EIKONXS program based on an efficient propagation $\operatorname{method}^{40}$ for the direct reaction $\mathrm{Mg}^{2+}\left({ }^{1} \mathrm{~S}_{\mathrm{g}}\right)+\mathrm{O}\left({ }^{3} \mathrm{P}_{\mathrm{g}}\right) \rightarrow \mathrm{X}^{3} \Sigma^{-}$ $\mathrm{Mg}^{+}\left({ }^{2} \mathrm{~S}_{\mathrm{g}}\right)+\mathrm{O}^{+}\left({ }^{4} \mathrm{~S}_{\mathrm{u}}\right)$ in a wide range of collision energies, from $1 \mathrm{eV}$ to $10^{3} \mathrm{eV}$. The coupled equations have been solved with a step size such that an accuracy of $10^{-4}$ for the symmetry of the $S$ matrix is achieved with the origin of electronic coordinates at the centre-of-mass of the collision system. However, the approximation of a straight-line trajectory for the nucleus motion, used in semi-classical approaches, may be questionable at low collision energies. Indeed, the approximation of a classical motion for the nucleus requires that the wavelength $\lambda$ associated with the nuclear motion remains small compared with the size of the interacting region. A quantum wave packet propagation treatment has thus been developed at lower collision energies in the eV range. The collision matrix elements are extracted from wave packets by the flux method with a complex absorbing potential. ${ }^{39,41}$ A priori, semi-classical approaches are only valid for incident energies greater than a few eV $\mathrm{amu}^{-1} .^{42}$ Nevertheless, the comparison of time-dependent quantal wave packet and semi-classical approaches for charge transfer processes showed that the latter approach may be extended to lower collision energies with acceptable accuracies. ${ }^{39}$
The rate constants $k(T)$ were then calculated for a series of temperatures by averaging the corresponding cross sections $\sigma(E)$ over a Maxwellian velocity distribution at temperature $T:{ }^{43}$

$$
k(T)=\left(\frac{8}{\pi \mu}\right)^{1 / 2}\left(\frac{1}{k_{\mathrm{B}} T}\right)^{3 / 2} \int_{0}^{\infty} E \sigma(E) \exp \left(-\frac{E}{k_{\mathrm{B}} T}\right) \mathrm{d} E
$$

\section{Electronic structure results and spectroscopy}

\section{Nature of the electronic ground state of $\mathrm{MgO}^{2+}$}

According to our theoretical calculations, the ground state of $\mathrm{MgO}^{2+}$ is a ${ }^{3} \Sigma^{-}$state. This confirms the earlier predictions of Kolbuszewski and Wright ${ }^{24}$ using the multireference singleand double-excitation (MRD-CI) technique. Fig. 2 displays the potential energy curve of this ground state along the internuclear distance $R_{\mathrm{MgO}}$. At the MRCI/aug-cc-pV5Z level, the minimum of $\mathrm{MgO}^{2+}\left(\mathrm{X}^{3} \Sigma^{-}\right)$is located $\sim 0.45 \mathrm{eV}$ below the lowest dissociation limit $\mathrm{Mg}^{+}\left({ }^{2} \mathrm{~S}_{\mathrm{g}}\right)$ and $\mathrm{O}^{+}\left({ }^{4} \mathrm{~S}_{\mathrm{u}}\right)$. Hence this dication is thermodynamically stable. We compute a potential well of $\sim 1.5 \mathrm{eV}$ that supports several vibrational levels.

The shape of the $\mathrm{MgO}^{2+}\left(\mathrm{X}^{3} \Sigma^{-}\right)$potential is not conventional. Indeed, it is composed of a Morse-type potential for $R_{\mathrm{MgO}}<$ $22.09 \mathrm{bohr}$ and a $1 / R$ type potential for $R_{\mathrm{MgO}}>22.09 \mathrm{bohr}$. This is due to an avoided crossing between the covalent charge retaining potential correlating to $\mathrm{Mg}^{2+}\left({ }^{1} \mathrm{~S}_{\mathrm{g}}\right)+\mathrm{O}\left({ }^{3} \mathrm{P}_{\mathrm{g}}\right)$ and the repulsive potential due to Coulombic interaction correlating to the charge separation limit $\mathrm{Mg}^{+}\left({ }^{2} \mathrm{~S}_{\mathrm{g}}\right)+\mathrm{O}^{+}\left({ }^{4} \mathrm{~S}_{\mathrm{u}}\right)$. Consequently, the vibrational levels of $\mathrm{MgO}^{2+}\left(\mathrm{X}^{3} \Sigma^{-}\right)$located below this asymptote are thermodynamically stable. For those located above this asymptote, they will be merely long-lived. This type of potential was recently found by Corral et al. ${ }^{44}$ for the $\mathrm{GaF}^{2+}$ dication. In contrast, the Morse-type to Coulomb repulsive

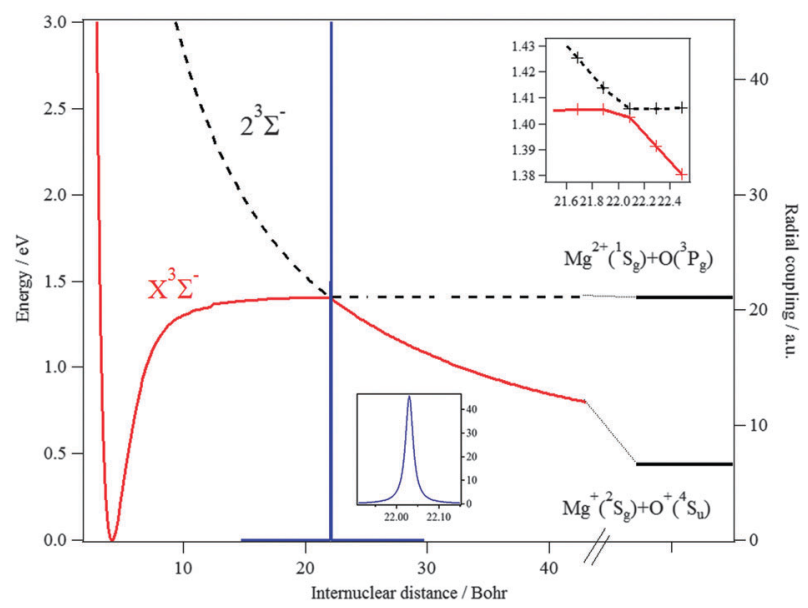

Fig. $2 \mathrm{MRCl}$ potential energy curves of the two lowest ${ }^{3} \Sigma^{-}$states of $\mathrm{MgO}^{2+} \mathrm{vs}$. the internuclear distance. The reference energy is the energy at the $\mathrm{MgO}^{2+}\left(\mathrm{X}^{3} \Sigma^{-}\right)$ minimum. The upper inset represents an enlargement at the avoided crossing region between these two states; the radial coupling between them is also given in the lower inset. See the text for more details. 
Table 1 Equilibrium distances ( $R_{\mathrm{e}}$, in bohr) and dominant electronic configurations of the $\mathrm{MgO}^{2+}$ electronic states correlating to the four lowest dissociation limits. $T_{\mathrm{a}}$ (in $\mathrm{eV}$ ) corresponds to the $\mathrm{MRCl}$ adiabatic excitation energy including the zero point vibrational correction at the anharmonic level. We give in parentheses the leading $\mathrm{Cl}$ coefficient in the CASSCF wavefunction. $D_{\mathrm{e}}$ (in eV) is calculated as the difference between the energy of the electronic state at equilibrium and the energy at the maximum of the potential barrier (cf. Fig. 2)

\begin{tabular}{llll}
\hline States & Electron configuration & $R_{\mathrm{e}}$ & $T_{\mathrm{a}}$ \\
\hline $\mathrm{X}^{3} \Sigma^{-}$ & $(5 \sigma)^{2}(6 \sigma)^{2}(2 \pi)^{2}(0.967)$ & 4.117 & $D_{\mathrm{e}}$ \\
$1^{3} \Pi$ & $(5 \sigma)^{2}(6 \sigma)^{1}(2 \pi)^{3}(0.974)$ & 4.179 & 0.00 \\
$1^{1} \Delta$ & $(5 \sigma)^{2}(6 \sigma)^{2}(2 \pi)^{2}(0.975)$ & 4.086 & 0.95 \\
$1^{1} \Pi$ & $(5 \sigma)^{2}(6 \sigma)^{1}(2 \pi)^{3}(0.974)$ & 4.310 & 4.123 \\
$1^{1} \Sigma^{+}$ & $(5 \sigma)^{2}(6 \sigma)^{2}(2 \pi)^{2}(0.669)$ and $(5 \sigma)^{2}(2 \pi)^{4}(0.301)$ & & 0.43 \\
$1^{5} \Sigma^{-a}$ & $(5 \sigma)^{2}(6 \sigma)^{1}(7 \sigma)^{1}(2 \pi)^{2}(0.973)$ & & 1.37 \\
$2^{3} \Sigma^{-a}$ & $(5 \sigma)^{2}(6 \sigma)^{1}(7 \sigma)^{1}(2 \pi)^{2}(0.936)$ & & \\
$1^{3} \Delta^{a}$ & $(5 \sigma)^{2}(6 \sigma)^{1}(7 \sigma)^{1}(2 \pi)^{2}(0.980)$ & & \\
$2^{3} \Pi^{a}$ & $(5 \sigma)^{2}(6 \sigma)^{2}(7 \sigma)^{1}(2 \pi)^{1}(0.747)$ and $(5 \sigma)^{2}(7 \sigma)^{1}(2 \pi)^{3}(0.218)$ & \\
$2^{1} \Sigma^{+}$ & $(5 \sigma)^{2}(2 \pi)^{4}(0.592)$ and $(5 \sigma)^{2}(6 \sigma)^{2}(2 \pi)^{2}(0.341)$ & 4.663 & \\
${ }^{a}$ Repulsive states. & & & \\
\hline
\end{tabular}

potential change is occurring here at very large internuclear distances (at $\sim 22$ bohr for $\mathrm{MgO}^{2+}$ and at $\sim 10$ bohr for $\mathrm{GaF}^{2+}$ ).

The $\mathrm{MgO}^{2+}$ ground state is obtained after removal of two electrons from the outermost $2 \pi$-orbital of the neutral molecule (Table 1). This molecular orbital is bonding in nature. This is associated with a lengthening of the $R_{\mathrm{MgO}}$ distance upon double ionization of the neutral molecule $\left(R_{\mathrm{e}}\right.$ of $\mathrm{MgO}\left(\mathrm{X}^{1} \Sigma^{+}\right)=$ $1.749 \AA^{45}$ and $R_{\mathrm{e}}$ of $\mathrm{MgO}^{2+}\left(\mathrm{X}^{3} \Sigma^{-}\right)=2.178 \AA$, Table 2$)$. The nature of the wavefunction of this electronic state changes drastically at the avoided crossing with the upper $2^{3} \Sigma^{-}$state (Fig. 2). Indeed, it is dominantly described by the $(5 \sigma)^{2}(6 \sigma)^{2}(2 \pi)^{2}$ electron configuration for $R_{\mathrm{MgO}}<22.09$ bohr. For $R_{\mathrm{MgO}}>22.09 \mathrm{bohr}$, this electronic state corresponds to the $(5 \sigma)^{2}(6 \sigma)^{1}(7 \sigma)^{1}(2 \pi)^{2}$ electron configuration. For the $2^{3} \Sigma^{-}$state, we have the reverse situation.

\section{Double ionization potential of $\mathrm{MgO}$}

Our MRCI/aug-cc-pV5Z vertical double ionization energy (VDIE) is computed to be $24.39 \mathrm{eV}$. VDIE corresponds to the energy difference between the energy of the dicationic ground state and the energy of the neutral ground state at the equilibrium geometry of the neutral molecule. The coupled clusters approach $\left((\mathrm{R}) \operatorname{CCSD}(\mathrm{T})^{46}\right)$ with the aug-cc-pV5Z basis set leads to a VDIE of $24.43 \mathrm{eV}$. The adiabatic double ionization energy (ADIE) of $\mathrm{MgO}$ is evaluated as the difference between the energy of $\mathrm{MgO}^{2+}\left(\mathrm{X}^{3} \Sigma^{-}, \mathrm{v}^{++}=0\right)$ and the energy of $\mathrm{MgO}\left(\mathrm{X}^{1} \Sigma^{+}, \mathrm{v}^{\prime \prime}=0\right)$. At the MRCI/aug-cc-pV5Z level of theory, we calculate ADIE = $23.52 \mathrm{eV}$. The (R)CCSD(T)/aug-cc-pV5Z value is $23.50 \mathrm{eV}$. ADIE is distinctly smaller than VDIE by $\sim 1 \mathrm{eV}$ because of the larger equilibrium distance of $\mathrm{MgO}^{2+} \mathrm{X}^{3} \Sigma^{-}$compared to $\mathrm{MgO} \mathrm{X}{ }^{1} \Sigma^{+}$. This leads to unfavourable Franck-Condon (FC) factors upon double ionization of the neutral molecule as illustrated in Fig. 3 where the vertical line corresponds to the middle of the FC region i.e. the maximum of the $\mathrm{MgO}\left(\mathrm{X}^{1} \Sigma^{+}, \mathrm{v}^{\prime \prime}=0\right)$ wavefunction.

\section{Electronic states of $\mathrm{MgO}^{2+}$}

Fig. 3 displays the MRCI PECs of the singlet, triplet and quintet electronic states of $\mathrm{MgO}^{2+}$ correlating to the four lowest dissociation limits: $\mathrm{O}^{+}\left({ }^{4} \mathrm{~S}_{\mathrm{u}}\right)+\mathrm{Mg}^{+}\left({ }^{2} \mathrm{~S}_{\mathrm{g}}\right), \mathrm{O}\left({ }^{3} \mathrm{P}_{\mathrm{g}}\right)+\mathrm{Mg}^{2+}\left({ }^{1} \mathrm{~S}_{\mathrm{g}}\right), \mathrm{O}\left({ }^{1} \mathrm{D}_{\mathrm{g}}\right)+$ $\mathrm{Mg}^{2+}\left({ }^{1} \mathrm{~S}_{\mathrm{g}}\right)$ and $\mathrm{O}^{+}\left({ }^{2} \mathrm{D}_{\mathrm{u}}\right)+\mathrm{Mg}^{+}\left({ }^{2} \mathrm{~S}_{\mathrm{g}}\right)$. Table 1 lists their dominant electronic configurations quoted at the $\mathrm{MgO}^{2+} \mathrm{X}^{3} \Sigma^{-}$equilibrium distance (i.e. $R_{\mathrm{MgO}}=4.117$ bohr) together with the leading CI coefficients of the corresponding CASSCF wavefunction. The energy position of the lowest dissociation limit, $\mathrm{O}^{+}\left({ }^{4} \mathrm{~S}_{\mathrm{u}}\right)+$ $\mathrm{Mg}^{+}\left({ }^{2} \mathrm{~S}_{\mathrm{g}}\right)$, is deduced from MRCI calculations on the separated

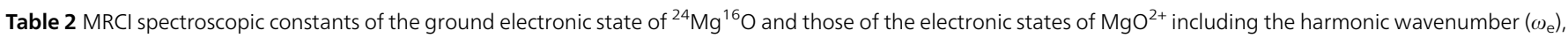
the anharmonic terms $\left(\omega_{\mathrm{e}} x_{\mathrm{e}}, \omega_{\mathrm{e}} y_{\mathrm{e}}\right)$, the rotational constants $\left(B_{\mathrm{e}}, \alpha_{\mathrm{e}}\right)$. All values are in $\mathrm{cm}^{-1}$

\begin{tabular}{|c|c|c|c|c|c|}
\hline State & $\omega_{\mathrm{e}}$ & $\omega_{\mathrm{e}} x_{\mathrm{e}}$ & $\omega_{\mathrm{e}} y_{\mathrm{e}}$ & $B_{\mathrm{e}}$ & $\alpha_{\mathrm{e}}$ \\
\hline \multicolumn{6}{|l|}{$\mathrm{MgO}$} \\
\hline $\mathrm{X}^{1} \Sigma^{+a}$ & 780.0 & 7.42 & 0.310 & 0.564 & $5.12 \times 10^{-3}$ \\
\hline $\mathrm{X}^{1} \Sigma^{+b}$ & 796.8 & 9.82 & 0.213 & 0.570 & $6.14 \times 10^{-3}$ \\
\hline $\mathrm{X}^{1} \Sigma^{+c}$ & $785.2183(6)$ & $5.1327(3)$ & $1.649(7) \times 10^{-2}$ & $0.5748414(3)$ & $5.3223(3) \times 10^{-3}$ \\
\hline \multicolumn{6}{|l|}{$\mathrm{MgO}^{2+}$} \\
\hline $\mathrm{X}^{3} \Sigma^{-a}$ & 373.8 & 3.47 & $9.53 \times 10^{-3}$ & 0.370 & $5.01 \times 10^{-3}$ \\
\hline $\mathrm{X}^{3} \Sigma^{-b}$ & 375.8 & 3.46 & $6.41 \times 10^{-3}$ & 0.371 & $5.01 \times 10^{-3}$ \\
\hline $1^{3} \Pi$ & 272.1 & 5.50 & $1.45 \times 10^{-3}$ & 0.359 & $8.49 \times 10^{-3}$ \\
\hline $1^{1} \Delta$ & 384.2 & 3.67 & $5.50 \times 10^{-3}$ & 0.376 & $5.09 \times 10^{-3}$ \\
\hline $1^{1} \Pi$ & 252.4 & 4.10 & $-1.15 \times 10^{-2}$ & 0.338 & $7.14 \times 10^{-3}$ \\
\hline $1^{1} \Sigma^{+}$ & 323.5 & 5.79 & $-3.20 \times 10^{-2}$ & 0.369 & $7.32 \times 10^{-3}$ \\
\hline $2^{1} \Sigma^{+}$ & 186.6 & 1.46 & $3.81 \times 10^{-2}$ & 0.289 & $4.43 \times 10^{-3}$ \\
\hline
\end{tabular}

${ }^{a}$ This work. At the MRCI/aug cc-pV5Z level of theory. ${ }^{b}$ This work. At the (R)CCSD(T)/aug cc-pV5Z level of theory. For MgO, we compute $D_{0}=4.76 \mathrm{eV}$ and $R_{\mathrm{e}}=3.317$ bohr. ${ }^{c}$ Exp. ref. 64 . 


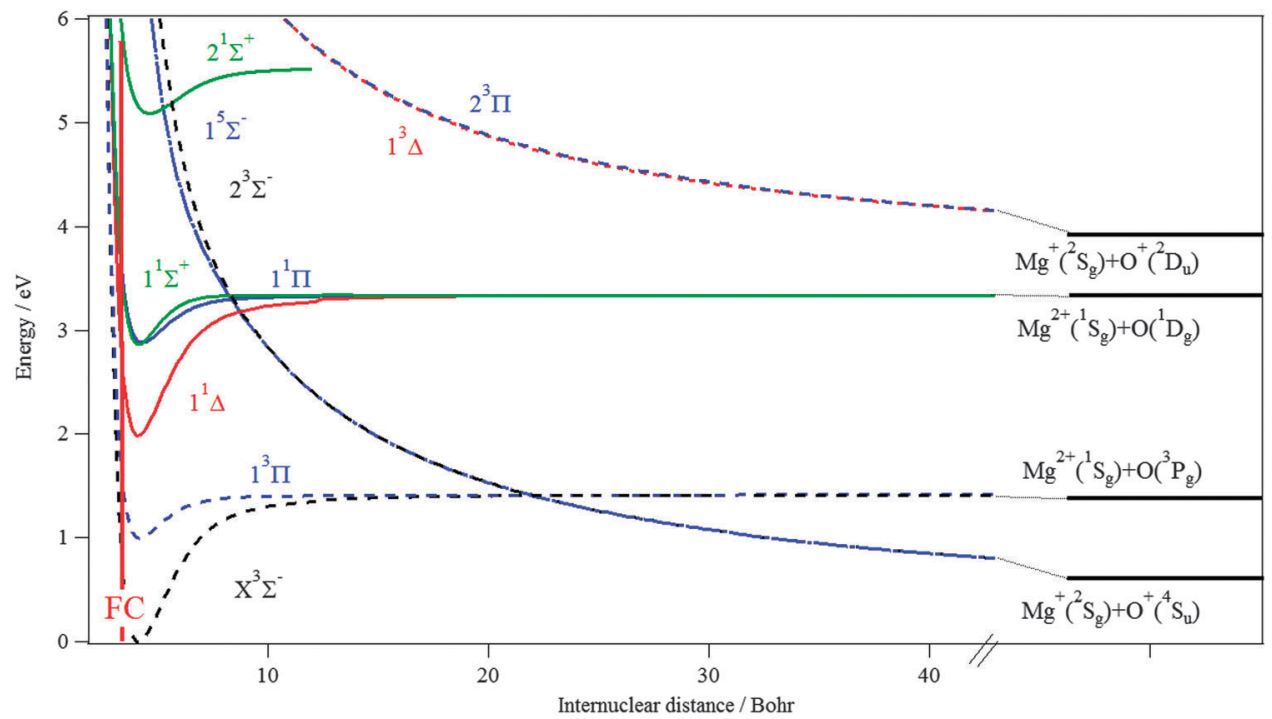

Fig. $3 \mathrm{MRCl}$ potential energy curves of the electronic states of $\mathrm{MgO}^{2+}$ correlating to the four lowest dissociation limits. The reference energy is the energy at the $\mathrm{MgO}^{2+}\left(\mathrm{X}^{3} \Sigma^{-}\right)$minimum. The vertical solid thick line corresponds to the middle of the Franck-Condon region $(\mathrm{FC})$ i.e. the maximum of the $\mathrm{MgO}\left(\mathrm{X}^{1} \Sigma^{+}, v^{\prime \prime}=0\right)$ vibrational wavefunction.

fragments. The higher limits were located using the experimental excitation energies and ionization energies of $\mathrm{O} \mathrm{O}^{+}$, $\mathrm{Mg}$ and $\mathrm{Mg}^{+}{ }^{47}$ These potentials are given as ESI.† Table 1 lists also the equilibrium distances, the adiabatic excitation energies and the binding energies $\left(D_{\mathrm{e}}\right)$ of the $\mathrm{MgO}^{2+}$ electronic states.

For the bound states, the present ordering and the nature of the electronic states are quite similar to those of the $\mathrm{LiO}^{+}, \mathrm{LiS}^{+}$, $\mathrm{NaO}^{+}, \mathrm{NaS}^{+}$and $\mathrm{BeO}^{2+}$ isovalent molecular ions. ${ }^{48-52}$ Indeed, Fig. 3 shows that the $\mathrm{MgO}^{2+}\left(\mathrm{X}^{3} \Sigma^{-}\right)$ground electronic state is followed by the $1^{3} \Pi$ state at $\sim 1 \mathrm{eV}$. Then, three bound singlet states are found i.e. the $1^{1} \Delta$ state at $2 \mathrm{eV}$ and the $1^{1} \Pi$ and $1^{1} \Sigma^{+}$ states at $\sim 3 \mathrm{eV}$, which are lying close to each other (Fig. 3 and Table 1). The main components of the $1^{3} \Pi$ and $1^{1} \Pi$ states are described by the $(6 \sigma)^{1}(2 \pi)^{3}$ electron configuration, whereas the wavefunctions of the $1^{1} \Delta$ and the $1^{1} \Sigma^{+}$states correspond to the $(2 \pi)^{2}$ electron configuration as in the ground state. At higher energies, we find the $2^{1} \Sigma^{+}$state (at $5 \mathrm{eV}$ ) which corresponds to the removal of two electrons from $6 \sigma \mathrm{MO}$. In addition, four repulsive states are found: $1^{5} \Sigma^{-}, 2^{3} \Sigma^{-}, 1^{3} \Delta$ and $2^{3} \Pi$. The $1^{5} \Sigma^{-}$ and the $2^{3} \Sigma^{-}$repulsive states are crossing the bound states. For the triplet, this results, as described above, into avoided cross$\operatorname{ing}$ (at $R_{\mathrm{AVC}} \sim 20.09 \mathrm{bohr}$ ) of the ground electronic state. At this crossing non-adiabatic effects are expected. Fig. 2 displays the radial coupling between these two states. As can be seen there, the coupling is non-zero only at the region of the crossing. The $\mathrm{X}^{3} \Sigma^{-}, 2^{3} \Sigma^{-}$and $1^{3} \Pi$ states are also coupled by spin-orbit and via rotational couplings. The corresponding spin-orbit and rotational integrals are displayed in Fig. 4 and 5. The drastic change in these integrals at $\sim R_{\mathrm{AVC}}$ is due to a change in wavefunctions' nature of the $\mathrm{X}^{3} \Sigma^{-}$and $2^{3} \Sigma^{-}$states. The $1^{5} \Sigma^{-}$ state is crossing the $1^{3} \Pi$ state accidently at $\sim R_{\mathrm{AVC}}$. Due to spin-orbit selection rules, only the $\left\langle 1^{3} \Pi\left|H^{\mathrm{SO}}\right| 1^{5} \Sigma^{-}\right\rangle$gives $a$ priori non-zero contribution. Nevertheless, this matrix element is evaluated close to zero at this crossing (Fig. 5). Therefore, the

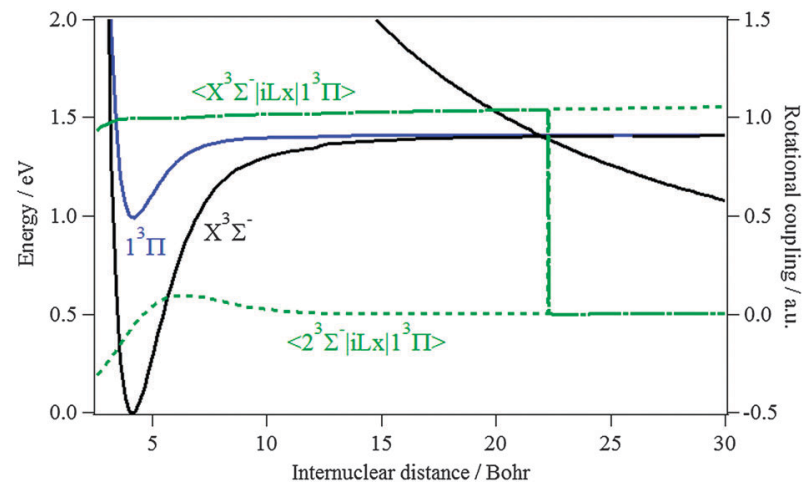

Fig. $4 \mathrm{MRCl}$ potential energy curves of the $\mathrm{X}^{3} \Sigma^{-}, 2^{3} \Sigma^{-}$and $1^{3} \Pi$ states of $\mathrm{MgO}^{2+}$ vs. the internuclear distance. The reference energy is the energy at the $\mathrm{MgO}^{2+}\left(X^{3} \Sigma^{-}\right)$minimum. We give the $\left\langle X^{3} \Sigma^{-}|i L x| 1^{3} \Pi\right\rangle$ (dashed dotted line) and $\left\langle 2^{3} \Sigma^{-}|i L x| 1^{3} \Pi\right\rangle$ (dashed line) rotational couplings vs. the internuclear distance.

quintet state has no role in the charge transfer reactions of interest.

\section{Spectroscopy}

Table 2 gives a set of spectroscopic constants for the ground state $\mathrm{X}^{1} \Sigma^{+}$of $\mathrm{MgO}$ and for the bound electronic states of $\mathrm{MgO}^{2+}$. This includes the harmonic wavenumbers $\left(\omega_{\mathrm{e}}\right)$, the anharmonic terms $\left(\omega_{\mathrm{e}} x_{\mathrm{e}}, \omega_{\mathrm{e}} y_{\mathrm{e}}\right)$ and the rotational constants $\left(B_{\mathrm{e}}, \alpha_{\mathrm{e}}\right)$. The spectroscopic constants are deduced from the derivatives of the potentials at their respective minima using the Dunham expansion term implemented in the Numerov algorithm. ${ }^{37}$ For MgO, our calculated MRCI equilibrium distance is $R_{\mathrm{e}}\left(\mathrm{MgO}, \mathrm{X}^{1} \Sigma^{+}\right)=$ $1.763 \AA$ A. Using the coupled clusters approach, we obtain $1.755 \AA$. These values agree with the experimental value of $1.749 \AA$ given in ref. 17. A good agreement is also obtained for the $\mathrm{MgO}$ harmonic wavenumber $\left(\omega_{\mathrm{e}}\right)$ using MRCI since our value differs 


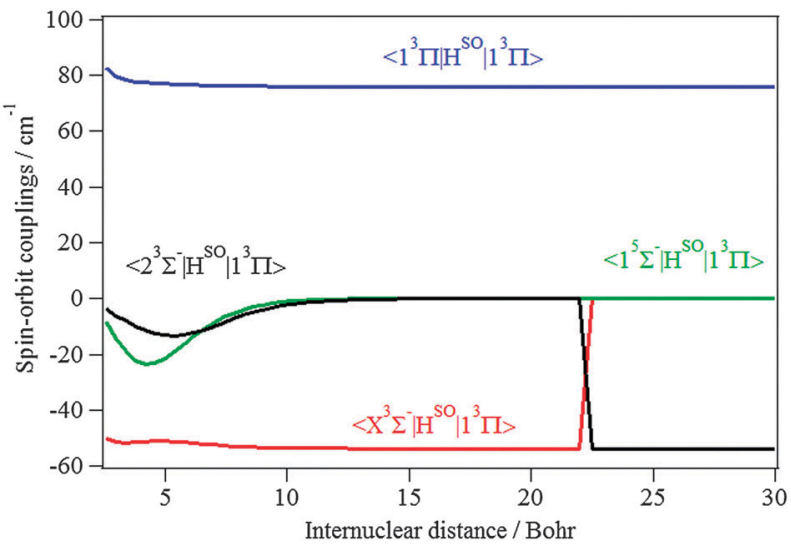

Fig. 5 Evolution along the internuclear distance of the non-vanishing spin-orbit couplings between the $X^{3} \Sigma^{-}, 1^{3} \Pi, 2^{3} \Sigma^{-}$and $1^{5} \Sigma^{-}$states.

by about $5 \mathrm{~cm}^{-1}$ from the experimental value (Table 2). The anharmonic terms $\left(\omega_{\mathrm{e}} x_{\mathrm{e}}, \omega_{\mathrm{e}} y_{\mathrm{e}}\right)$ and the rotational constants $\left(B_{\mathrm{e}}, \alpha_{\mathrm{e}}\right)$ show reasonable agreement with experiment. For the electronic states of the $\mathrm{MgO}^{2+}$ dication (Table 2), our data are predictive in nature and should be of similar precision as discussed for the neutral $\mathrm{MgO}$ molecule. The energies of the vibrational levels that could be supported by each bound electronic state can be deduced using the spectroscopic constants given in Table 2.

Fig. 5 displays the $\left\langle 1^{3} \Pi\left|\boldsymbol{H}^{\mathrm{SO}}\right| 1^{3} \Pi\right\rangle$ spin-orbit diagonal term evolution along the internuclear distance. This allows deducing the spin-orbit constant at equilibrium $A_{\mathrm{e}, \mathrm{so}}\left(1^{3} \Pi\right)$ of this state. This quantity is equal to the $\left\langle 1^{3} \Pi\left|\boldsymbol{H}^{\mathrm{SO}}\right| 1^{3} \Pi\right\rangle$ integral evaluated at the equilibrium distance of this electronic state. We compute $A_{\mathrm{e}, \mathrm{So}}\left(1^{3} \Pi\right)=77.5 \mathrm{~cm}^{-1}$. According to the wide discussion on the spin-orbit computations of $\mathrm{MgO}^{17}$ and $\mathrm{MgO}^{+}$(ref. 18) using our methodology and the comparison of our data to the experimental ones, we expect that $A_{\mathrm{e}, \mathrm{So}}\left(1^{3} \Pi\right)$ is accurate within $5 \%$.

\section{Cross sections}

Spin-orbit coupling being negligible in the energy range of interest, the electron spin can be assumed to be conserved during the collision process. For the present system, the charge transfer is thus driven only by triplet states. The calculations were carried out for the $2^{3} \Sigma^{-}$and $1^{3} \Pi$ states corresponding to the entry channel $\mathrm{Mg}^{2+}\left({ }^{1} \mathrm{~S}_{\mathrm{g}}\right)+\mathrm{O}\left({ }^{3} \mathrm{P}_{\mathrm{g}}\right)$ and the $\mathrm{Mg}^{+}\left({ }^{2} \mathrm{~S}_{\mathrm{g}}\right)+\mathrm{O}^{+}\left({ }^{4} \mathrm{~S}_{\mathrm{u}}\right)$ charge transfer channel along the $\mathrm{MgO}^{2+}\left(\mathrm{X}^{3} \Sigma^{-}\right)$potential, taking into account all the transitions induced by radial and rotational coupling matrix elements. The exit channel $\mathrm{Mg}^{+}\left({ }^{2} \mathrm{~S}_{g}\right)+$ $\mathrm{O}^{+}\left({ }^{4} \mathrm{~S}_{\mathrm{u}}\right)$ on the $\mathrm{X}^{3} \Sigma^{-}$state may be populated either by means of radial coupling with the $2^{3} \Sigma^{-}$state, or by rotational coupling with the $1^{3} \Pi$ state, both of them associated with the $\mathrm{Mg}^{2+}\left({ }^{1} \mathrm{~S}_{\mathrm{g}}\right)+$ $\mathrm{O}\left({ }^{3} \mathrm{P}_{\mathrm{g}}\right)$ entry channel. For symmetry reasons, the $1^{3} \Pi^{-}$ component interacts with the $\mathrm{X}^{3} \Sigma^{-}$state and the $2^{3} \Sigma^{-}$states. Taking into account statistical weights between $\Sigma$ and $\Pi$ states in the triplet manifold, the total charge transfer cross section $\left(\sigma_{\text {tot }}\right)$ may thus be expressed by:

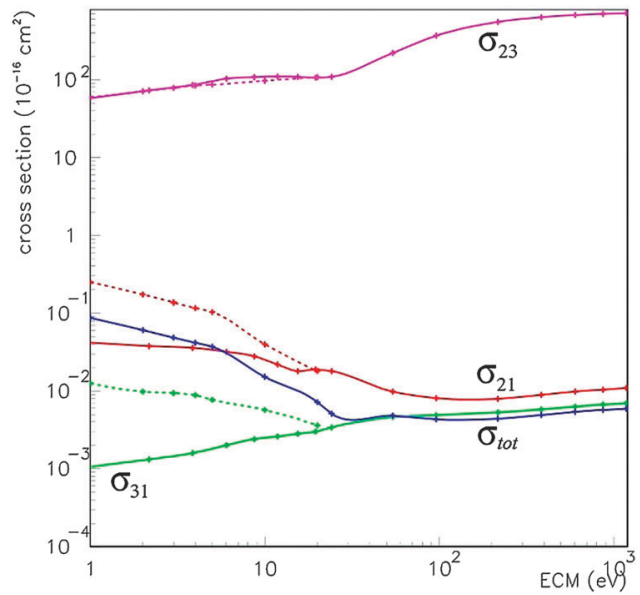

Fig. 6 Partial and total charge transfer cross sections for the $\mathrm{Mg}^{2+}+\mathrm{O}$ collision process vs. collision energy computed using the semi-classical (sc, cross sections full line) and wave packet ( $w p$, cross sections dashed line) approaches. $\sigma_{21}$ : partial charge transfer cross sections for the $2^{3} \Sigma^{-} \rightarrow X^{3} \Sigma^{-}$transition; $\sigma_{31}$ : partial charge transfer cross sections for $1^{3} \Pi^{-} \rightarrow X^{3} \Sigma^{-}$transition; $\sigma_{23}$ : partial charge transfer cross sections for $2^{3} \Sigma^{-} \rightarrow 1^{3} \Pi$ transition. $\sigma_{\text {tot }}$ total charge transfer cross sections. The exit channel leads to the $\mathrm{X}^{3} \Sigma^{-}$state.

$$
\sigma_{\text {tot }}=\frac{1}{3} \sigma_{21}+\frac{1}{3} \sigma_{31}
$$

where $\sigma_{21}$ corresponds to the $2^{3} \Sigma^{-} \rightarrow \mathrm{X}^{3} \Sigma^{-}$transition and $\sigma_{31}$ to the $1^{3} \Pi^{-} \rightarrow X^{3} \Sigma^{-}$transition. Both of them have a weight of $\frac{1}{3}$ since the $1^{3} \Pi^{+} \rightarrow \mathrm{X}^{3} \Sigma^{-}$transition gives no contribution to this charge transfer process.

The partial and total cross sections are displayed in Fig. 6. Both quantum and semi-classical treatments lead to similar values for the cross sections for collision energies in the centreof-mass (ECM) higher than $\sim 20-30 \mathrm{eV}$. This result is in quite good agreement with previous work on the $\mathrm{C}^{+}+\mathrm{S}$ collision system. ${ }^{39}$ For ECM $<20 \mathrm{eV}$, the semi-classical treatment cannot reproduce the trajectory effects, and distinct cross section evolutions are of course observables, in particular for the charge transfer cross sections. The cross sections $\sigma_{21}$ and $\sigma_{31}$ exhibit indeed an increase for decreasing collision energies in the quantum approach, which cannot be reproduced by a semi-classical treatment. The cross sections between the $2^{3} \Sigma^{-}$ and $1^{3} \Pi^{-}$levels corresponding to the $\mathrm{Mg}^{2+}\left({ }^{1} \mathrm{~S}_{\mathrm{g}}\right)+\mathrm{O}\left({ }^{3} \mathrm{P}_{\mathrm{g}}\right)$ entry channel are however in quite good agreement, even at very low energies. Anyway, the rate coefficients are computed from the total charge transfer cross sections, taking into account the quantum charge transfer cross sections at lower collision energies, completed by the semi-classical values for ECM $>20 \mathrm{eV}$. We compute a very regular variation of the charge transfer rate coefficients as shown in Table 3, which presents the rate constants in the $50 \leq T \leq 10000 \mathrm{~K}$ range. At $T=50 \mathrm{~K}$, the rate constant is $\sim 0.39 \times 10^{-12} \mathrm{~cm}^{3} \mathrm{~s}^{-1}$, which increases to $0.35 \times 10^{-11} \mathrm{~cm}^{3} \mathrm{~s}^{-1}$ at $T=10000 \mathrm{~K}$.

\section{Atmospheric implications}

The consideration of the planetary abundances of the different species such as $\mathrm{O}, \mathrm{O}^{+}, \mathrm{O}_{2}{ }^{+}$in the planetary atmospheres of the 
Table 3 Rate constants $\left(k\right.$ in $\left.\mathrm{cm}^{3} \mathrm{~s}^{-1}\right)$ for the charge transfer reaction $\mathrm{Mg}^{2+}\left({ }^{1} \mathrm{~S}_{\mathrm{g}}\right)+$ $\mathrm{O}\left({ }^{3} \mathrm{P}_{\mathrm{g}}\right) \rightarrow \mathrm{Mg}^{+}\left({ }^{2} \mathrm{~S}_{\mathrm{g}}\right)+\mathrm{O}^{+}\left({ }^{4} \mathrm{~S}_{\mathrm{u}}\right)$ vs. temperature $(T$ in $\mathrm{K})$. In these calculations, we considered the total cross sections from the wavepacket computations for collision energies from 1 to $20 \mathrm{eV}$ and the semi-classical cross sections for collision energies greater than $20 \mathrm{eV}$

\begin{tabular}{ll}
\hline$T$ & $k \times 10^{12}$ \\
\hline 50 & 0.39 \\
80 & 0.49 \\
100 & 0.55 \\
150 & 0.67 \\
200 & 0.77 \\
300 & 0.94 \\
400 & 1.08 \\
500 & 1.21 \\
600 & 1.31 \\
700 & 1.41 \\
800 & 1.50 \\
900 & 1.59 \\
1000 & 1.67 \\
2000 & 2.25 \\
3000 & 2.62 \\
4000 & 2.88 \\
5000 & 3.06 \\
6000 & 3.20 \\
7000 & 3.30 \\
8000 & 3.38 \\
9000 & 3.44 \\
10000 & 3.48 \\
\hline
\end{tabular}

solar system may be analyzed with regard to the abundances of neutral and ionic $\mathrm{Mg}$ in order to assess the efficiency of the possible reactions involving magnesium entities. As to the measured and calculated rate constants, the large $\mathrm{Mg}^{+} / \mathrm{Mg}$ ratio observed in the earth atmosphere ${ }^{6,7}$ was correlated mainly to the efficient $\mathrm{Mg}+\mathrm{O}_{2}^{+} \rightarrow \mathrm{Mg}^{+}+\mathrm{O}_{2}$ charge transfer reaction, whose rate constant reaches $1.2 \times 10^{-9} \mathrm{~cm}^{3} \mathrm{~s}^{-1}$ at $T=300 \mathrm{~K}$ according to laboratory measurements. Nevertheless, the atmospheric $\mathrm{Mg}^{+}$layer abundance is maximum for an altitude of $\sim 95 \mathrm{~km}^{8}$ i.e. in the lower limit of the thermosphere and more specifically in the vicinity of the ionosphere, where ionmolecule reactions may be important and the temperature reaches $1500 \mathrm{~K}$ or higher. In addition, atomic $\mathrm{O}$ is abundant at these altitudes and it represents a major constituent. Therefore, reactions involving such species have to be taken into account. Even if the $\mathrm{Mg}^{2+}$ signal could not be detected in oxygen rich atmospheres, ${ }^{11}$ such an ion could be formed easily there (at least after double photoionizing the $\mathrm{Mg}$ atom ablated from the meteorites) and the charge transfer process $\mathrm{Mg}^{2+}+\mathrm{O} \rightarrow$ $\mathrm{Mg}^{+}+\mathrm{O}^{+}$could be a possible reaction for the predominance of $\mathrm{Mg}^{+}$ions. Presently, we estimate the rate constant of such a process to be about $0.22 \times 10^{-11} \mathrm{~cm}^{3} \mathrm{~s}^{-1}$ at $2000 \mathrm{~K}$, which is significant. Consequently, the implication of the doubly charged $\mathrm{MgO}^{2+}$ dication in the atmospheric chemistry cannot be ruled out, especially the long range charge transfer processes enlightened in previous sections. Accordingly, these processes should be included in the atmospheric chemical models involving the magnesium species.

A similar analysis may be extended to the atmospheres of the solar system planets. For Mars, the abundances of $\mathrm{Mg}$ and $\mathrm{Mg}^{+}$species appear to be maximum for an altitude of around $100 \mathrm{~km} \cdot{ }^{53,54}$ At this range of altitudes, the abundances of $\mathrm{O}, \mathrm{O}^{+}$ and $\mathrm{O}_{2}{ }^{+}$are also important. ${ }^{55,56}$ This clearly points out the correlation between $\mathrm{Mg}$ and oxygen species either neutral or ionic, and corroborates the importance of the $\mathrm{Mg}^{2+}+\mathrm{O} \rightarrow \mathrm{Mg}^{+}+$ $\mathrm{O}^{+}$reaction in the martian chemistry, together with the $\mathrm{Mg}+$ $\mathrm{O}_{2}{ }^{+} \rightarrow \mathrm{Mg}^{+}+\mathrm{O}_{2}$ reaction. This is most likely the case in the atmospheres of Venus ${ }^{57}$ and of Titan ${ }^{58}$ where these processes may occur at even higher altitudes (around 600-700 km).

\section{Conclusions}

High-quality $a b$ initio potential energy curves for the lowest electronic states of the $\mathrm{MgO}^{2+}$ dication have been performed. Our theoretical results confirm the observation of the long-lived metastable dication $\mathrm{MgO}^{2+}$ in the experiment by Franzreb and Williams (see the mass spectrum in Fig. 1). Using these potentials we have deduced a set of accurate spectroscopic data for this dication. Our theoretical results should be useful in guiding future experimental spectroscopic work and its interpretation. The spectroscopy of this dication in gas phase can be, for instance, investigated using standard spectroscopic techniques, such as the Threshold Photoelectrons Coincidence (TPEsCO) method $^{59-62}$ or the time-of-flight photoelectron photoelectron coincidence (TOF-PEPECO) technique. ${ }^{63}$

In addition, we computed the spin-orbit, rotational and radial couplings between the lowest $\mathrm{MgO}^{2+}$ electronic states. Our potentials and couplings are then used to deduce the cross sections for the $\mathrm{Mg}^{2+}+\mathrm{O} \rightarrow \mathrm{Mg}^{+}+\mathrm{O}^{+}$charge transfer reaction which could have atmospheric implications. Indeed, the $\mathrm{Mg}^{2+}\left({ }^{1} \mathrm{~S}_{\mathrm{g}}\right)+\mathrm{O}\left({ }^{3} \mathrm{P}_{\mathrm{g}}\right) \rightarrow \mathrm{Mg}^{+}\left({ }^{2} \mathrm{~S}_{\mathrm{g}}\right)+\mathrm{O}^{+}\left({ }^{4} \mathrm{~S}_{\mathrm{u}}\right)$ charge transfer appears to be a possible reaction for the formation of $\mathrm{Mg}^{+}$ions in planetary atmospheres and should be considered in their modelling. The present work should motivate new experimental investigations of the reactions of interest in order to measure their rate constants and confirm the present conclusions. The evolution of the rate constant over the temperature domain we investigated may be useful for that purpose.

\section{Acknowledgements}

We thank Klaus Franzreb and Peter Williams (Arizona State University, USA) for permission to show their experimental results as Fig. 1 and Jean Lilensten (Université Joseph Fourier, Grenoble France) for helpful discussions. M.H. thanks financial support from the PCMI program (INSU, CNRS, France) and MCBM the support of the COST action CM0805 'Chemical Cosmos'.

\section{References}

1 C. B. Dreyer, J. W. Daily, A. Abbud-Madrid and M. C. Branch, Appl. Opt., 2001, 40, 2561.

2 J. M. C. Plane, Chem. Rev., 2003, 103, 4963.

3 R. P. Wayne, Chemistry of Atmospheres, Oxford Press, New York, 2nd edn, 1995.

4 B. Mason, Handbook of Elemental Abundances in Meteorites, Gordon and Breach, New York, 1971.

5 J. M. C. Plane, Int. Rev. Phys. Chem., 1991, 10, 55.

6 J. G. Anderson and C. A. Barth, J. Geophys. Res., 1971, 76, 3723. 
7 J. Gardner, R. A. Viereck, E. Murad, D. Knecht, C. P. Pike, L. Broadfoot and E. R. Anderson, Geophys. Res. Lett., 1995, 22, 2119.

8 C. L. Whalley, J. C. Gomez Martin, T. G. Wright and J. M. C. Plane, Phys. Chem. Chem. Phys., 2011, 13, 6352.

9 B. R. Rowe, D. W. Fahey, E. E. Ferguson and F. C. Fehsenfeld, J. Chem. Phys., 1981, 75, 3325.

10 S. Nishigaki, S. Onda, S. Kunitomo, M. Inoue and T. Noda, Nucl. Instrum. Methods, 1995, B95, 307.

11 A. Benninghoven and L. Weidmann, Surf. Sci., 1974, 41, 483.

12 W. J. McNeil, S. T. Lai and E. Murad, J. Geophys. Res., 1996, 101, 5251. 13 E. E. Ferguson, Radio Sci., 1972, 7, 397.

14 O. Yazidi, A. Ben Houria, Z. Ben Lakhdar, M. L. Senent and M. Hochlaf, Chem. Phys., 2008, 348, 215.

15 A. Ben Houria, O. Yazidi, N. Jaidane, M. L. Senent and M. Hochlaf, J. Chem. Phys., 2012, 136, 024316.

16 K. G. Spears, F. C. Fehsenfeld, M. McFarland and E. E. Ferguson, J. Chem. Phys., 1972, 56, 2562.

17 A. Maatouk, A. Ben Houria, O. Yazidi, N. Jaidane and M. Hochlaf, J. Chem. Phys., 2010, 133, 144302.

18 A. Maatouk, A. Ben Houria, O. Yazidi, N. Jaidane and M. Hochlaf, J. Phys. B: At., Mol. Opt. Phys., 2011, 44, 225101.

19 Klaus Franzreb and Peter Williams, unpublished experimental results, 2004-2009, Arizona State University; please see also their summary list in the ESI of ref. 20 at: http://www.rsc.org/suppdata/cp/ c1/c1cp21566c/c1cp21566c.pdf.

20 V. Brites, K. Franzreb, J. N. Harvey, S. G. Sayres, M. W. Ross, D. E. Blumling, A. W. Castleman, Jr and M. Hochlaf, Phys. Chem. Chem. Phys., 2011, 13, 15233.

21 A. Vella, B. Mazumder, G. Da Costa and B. Deconihout, J. Appl. Phys., 2011, 110, 044321.

22 Angela Vella, personal communication, 2011.

23 P. Dai, S. McCullough-Catalano, M. Bolton, A. D. Jones and C. B. Lebrilla, Int. J. Mass Spectrom. Ion Processes, 1995, 144, 67.

24 M. Kolbuszewski and J. S. Wright, Chem. Phys. Lett., 1994, 218, 338. 25 T. H. Dunning, J. Chem. Phys., 1989, 90, 1007.

26 Unofficial set from D. Feller for Mg, https://bse.pnl.gov/bse/portal.

27 D. E. Woon and T. H. Dunning, Jr., unpublished, https://bse.pnl. gov/bse/portal.

28 R. A. Kendall, T. H. Dunning, Jr and R. J. Harrison, J. Chem. Phys., 1992, 96, 6796.

29 P. J. Knowles and H.-J. Werner, Chem. Phys. Lett., 1985, 115, 259.

30 H.-J. Werner and P. J. Knowles, J. Chem. Phys., 1985, 82, 5053.

31 H. J. Werner and P. J. Knowles, J. Chem. Phys., 1988, 89, 5803.

32 P. J. Knowles and H.-J. Werner, Chem. Phys. Lett., 1988, 145, 514.

33 H.-J. Werner, P. J. Knowles, G. Knizia, F. R. Manby, M. Schütz, P. Celani, T. Korona, R. Lindh, A. Mitrushenkov, G. Rauhut, K. R. Shamasundar, T. B. Adler, R. D. Amos, A. Bernhardsson, A. Berning, D. L. Cooper, M. J. O. Deegan, A. J. Dobbyn, F. Eckert, E. Goll, C. Hampel, A. Hesselmann, G. Hetzer, T. Hrenar, G. Jansen, C. Köppl, Y. Liu, A. W. Lloyd, R. A. Mata, A. J. May, S. J. McNicholas, W. Meyer, M. E. Mura, A. Nicklaß, D. P. O'Neill, P. Palmieri, K. Pflüger, R. Pitzer, M. Reiher, T. Shiozaki, H. Stoll, A. J. Stone, R. Tarroni, T. Thorsteinsson, M. Wang and A. Wolf, MOLPRO Version 2010, is a package of ab initio programs.

34 R. Llusar, M. Casarrubios, Z. Barandiarán and L. Seijo, J. Chem. Phys., 1996, 105, 5321.

35 T. Zeng, D. G. Fedorov, M. W. Schmidt and M. Klobukowski, J. Chem. Phys., 2011, 134, 214107.
36 M. Schweizer, H.-J. Werner, P. J. Knowles and P. Palmieri, Mol. Phys., 2000, 98, 1823.

37 B. Numerov. Publs. observatoire central astrophys. Russ. v. 2. 1933, p. 188.

38 J. W. Cooley, Math. Comput., 1961, 15, 363.

39 A. Chenel, E. Mangaud, Y. Justum, D. Talbi, M.-C. BacchusMontabonel and M. Desouter-Lecomte, J. Phys. B: At., Mol. Opt. Phys., 2010, 43, 245701.

40 R. J. Allan, C. Courbin, P. Salas and P. Wahnon, J. Phys. B: At., Mol. Opt. Phys., 1990, 23, L461.

41 J. Loreau, K. Sodoga, D. Lauvergnat, M. Desouter-Lecomte and N. Vaeck, Phys. Rev. A, 2010, 82, 012708.

42 M. C. Bacchus-Montabonel, C. Courbin and R. McCarroll, J. Phys. B: At., Mol. Opt. Phys., 1991, 24, 4409.

43 E. Baloïtcha, M. Desouter-Lecomte, M. C. Bacchus-Montabonel and N. Vaeck, J. Chem. Phys., 2001, 114, 8741.

44 I. Corral, A. Palacios and M. Yanez, Phys. Chem. Chem. Phys., 2011, 13, 18365-18372.

45 K. P. Huber and G. Herzberg, Molecular Spectra and Molecular Structure, Van Nostrand Reinhold, New York, 1979 and references therein.

46 P. J. Knowles, C. Hampel and H.-J. Werner, J. Chem. Phys., 1993, 99, 5219, Erratum: J. Chem. Phys., 2000, 112, 3106.

$47 \mathrm{http}: / /$ webbook.nist.gov.

48 P. Soldan, E. P. F. Lee, S. D. Gamblin and T. G. Wright, Phys. Chem. Chem. Phys., 1999, 1, 4947.

49 F. Khadri, H. Ndome, S. Lahmar, Z. Ben Lakhdar and M. Hochlaf, J. Mol. Spectrosc., 2006, 237, 232.

50 F. Khadri and M. Hochlaf, Eur. Phys. J. D, 2012, 66, 145.

51 J. Fišer, K. Franzreb, J. Lörincík and P. Williams, Eur. J. Mass Spectrom., 2009, 15, 315.

52 E. P. F. Lee, P. Soldán and T. G. Wright, Chem. Phys. Lett., 2001, $347,481$.

53 G. J. Molina-Cuberos, O. Witasse, J.-P. Lebreton, R. Rodrigo and J. J. López-Moreno, Planet. Space Sci., 2003, 51, 239.

54 W. D. Pesnell, J. Geophys. Res., 2000, 105, 1695.

55 Jean Lilensten, Mariner and Viking data, private communication.

56 R. Thissen, O. Witasse, O. Dutuit, C. Simon Wedlund, G. Gronoff and J. Lilensten, Phys. Chem. Chem. Phys., 2011, 13, 18264.

57 O. Witasse, T. Carvens, M. Mendillo, L. Moses, A. Kliore, A. F. Nagy and T. Breus, in Comparative Aeronomy, ed. A. F. Nagy, A. Balogh, T. E. Cravens, M. Mendillo and I. Müller-Wodarg, Springer, London, 2008, ISBN-978-0-387-87824-9.

58 G. J. Molina-Cuberos, H. Lammer, W. Stumptner, K. Schwingenschuh, H. O. Rucker, J. J. Lopez-Moreno, R. Rodrigo and T. Tokano, Planet. Space Sci., 2001, 49, 143.

59 G. Dawber, A. G. McConkey, L. Avaldi, M. A. MacDonald, G. C. King and R. I. Hall, J. Phys. B: At., Mol. Opt. Phys., 1994, 27, 2191.

60 A. J. Yencha, G. C. King, M. C. A. Lopes, J. D. Bozek and N. Berrah, Chem. Phys. Lett., 1999, 315, 37.

61 M. Hochlaf, H. Kjeldsen, F. Penent, R. I. Hall, P. Lablanquie, M. Lavollée and J. H. D. Eland, Can. J. Phys., 1996, 74, 856.

62 R. I. Hall, G. Dawber, A. McConkey, M. A. MacDonald and G. C. King, Phys. Rev. Lett., 1992, 68, 2751.

63 J. H. D. Eland, Chem. Phys., 2003, 294, 171.

64 P. Mürtz, H. Thümmel, C. Pfelzer and W. Urban, Mol. Phys., 1995, 86, 513. 